\title{
Environmental pollutants and pediatric asthma
}

\author{
Alexandra Farrow \\ Brunel University, School of \\ Health Sciences \& Social \\ Care, Mary Seacole Building, \\ Uxbridge Middlesex \\ UB8 3PH, UK \\ Tel.: +441895268 759; \\ Fax: +441895269853; \\ E-mail: alexandra.farrow@ \\ brunel.ac.uk
}

\author{
'The question remains, therefore, as \\ to whether increased hygiene as \\ defined by apparent cleanliness \\ traits, may be a mask for increased \\ use of chemicals.'
}

It has been proposed that in industrially developed nations, the most serious diseases confronting children are the chronic conditions of multifactorial origin [1]. Asthma presents a complex and heterogeneous disorder with abnormal and inflamed airway mucosa and its incidence in children appears to have more than doubled in the last 50 years. This editorial will address some of the more recent research on the development of asthma in children, particularly in relation to low-level exposure to chemicals.

Indoor environmental factors, accepted as associated with an increased risk of developing pediatric asthma, include exposure to environmental tobacco smoke [2]. Exposure to allergens, and particularly to house dust mites, has also been found to increase the risk of respiratory symptoms. Allergen-reduction studies are difficult to undertake, but even when successful, have not always shown an improvement in symptoms. It is of interest that Butland et al. [3] and Frosh et al. [4] identified synthetic pillows with chemical constituents, and not feather pillows, to be associated with asthma symptoms and rhinitis attacks. A prospective 4-year Norwegian cohort study further supported these findings in reporting that the use of feather bedding quilts did not increase the risk of asthma or allergic rhinitis [5]. The chemical constituents of plastics have also been found in household dust, and studies suggest that plasticizers may be related to allergic diseases in children [6].

\section{The hygiene hypothesis}

While asthma is known to run in families, many patients, but by no means all, show signs and symptoms of IgE responses to common allergens. The hygiene hypothesis, proposed by
Strachan et al., is based on the idea that exposure to viruses, bacteria or their products in early life stimulates an immune response that results in acquired immunity being moved away from development of $\operatorname{IgE}$ responses to environmental and food allergens [7]. The hypothesis was based on the observation of an inverse association between the number of siblings and hayfever in adults among those in the 1960 UK birth cohort study. Strachan and colleagues suggested that a reduced exposure to infectious stimuli in families may result in atopic disease - the genetic potential to manifest the classic allergic diseases of atopic dermatitis, allergic rhinitis and asthma. Number of siblings was proposed as protective for allergic disease, siblings being seen as the source of infection.

\section{$\therefore$...feather bedding quilts did not increase the risk of asthma or allergic rhinitis.'}

Further evidence that general microbiological exposures may also be important in reducing atopy include research implicating farm animals in a protective role [8]. Innocuous bacterial exposures found in drinking water have also been proposed as exerting an influence on the developing immune system. Seiskari et al., demonstrate that high and intermediate levels of water contamination were associated with a reduced risk of atopy, independently from other factors [9]. Findings such as these indicate that we need better markers of bacterial or microbial exposure in early life.

\section{Mechanism of the hygiene hypothesis}

Recent research suggests that the mechanism of the hygiene hypothesis should be reconsidered. The Danish cohort reported that early clinically apparent infection did not explain an inverse association between number of siblings and atopic dermatitis [10]. Flohr et al., in reviewing the hygiene hypothesis, concluded that while a consistent inverse relationship between atopic dermatitis and increasing family size exists, this does not seem to be 
explained by a straightforward increased exposure to a single environmental pathogen [11]. The effect found with early day care, exposure to animals and endotoxins may be due to a nonpathogenic microbial stimulus of a chronic or recurrent nature. This might also explain the increased risk of childhood asthma associated with antibiotic use. In 2008, Bremner and colleagues, reporting on data from two large UK general practices, found that clinically apparent infections in the first year of life did not explain the inverse association between siblings and subsequent childhood hayfever [12]. While the number of older siblings was inversely associated with hayfever, sibling number did not predict clinically apparent infections in the first year of life. Bremner and colleagues concluded that supporters of a hygiene hypothesis need to look further than clinical infectious illnesses for an explanation of the increase in atopic diseases in developed countries.

'There is likely to be complex interaction of microbial agents and activation of immune responses in conjunction with an effect on allergic phenotypes.'

Immunological mechanisms associated with this hypothesis still remain unclear [13]. There is likely to be complex interaction of microbial agents and activation of immune responses in conjunction with an effect on allergic phenotypes. The route and duration of exposure, age of the individuals, genetic make-up and dose of microbial products will also influence the mechanism of response [14]. The main environmental influences for atopic diseases are probably occurring from organogenesis and throughout neonatal and adolescent development with further interactions between microbes and lifestyle factors [15]. The key changes to the immune system at the different stages of development would also alter any potential risk from environmental exposure to toxicants.

\section{Another explanation?}

However, there is another possible explanation that might elucidate the above. Occupational exposure to cleaning agents has been consistently associated with respiratory symptoms and particularly with irritant-induced asthma [16]. Nonoccupational exposure to chemicals within the indoor environment is important given that in developed countries the individual spends between 85 and $90 \%$ of their time indoors. For the neonate and the vulnerable infant this may be more than 95\%. Exposure to volatile organic compounds (VOCs) has been associated with a variety of symptoms, including respiratory and neurological developmental [17-18].

The extent to which chemical pollutants in any environment may be contributing to changing patterns of disease seen in children is unknown [1,19]. Over the past 50 years, more than 80,000 new synthetic chemical compounds have been developed. Each year in the USA, 2000-3000 new chemicals are brought to the US Environmental Protection Agency (EPA) for review prior to manufacture. Children are at risk of exposure to the 15,000 chemicals produced in quantities greater than 10,000 pounds per year and to the 2800 produced in quantities greater than 1 million pounds per year. These high-volume chemicals have the greatest potential for dispersion in air, water, food and buildings, including homes and schools [19]. Of the high-volume chemicals, only $43 \%$ have been tested for potential human toxicity, and only $7 \%$ have been studied for their possible effects on development $[20,21]$. It has been known for more than a decade that exposure to the mixture of VOCs present in indoor air, which include many hazardous air pollutants such as aromatic and chlorinated organic compounds, can irritate the mucus membrane in the respiratory tract in both healthy and sensitive individuals [22].

\section{'The hygiene hypothesis, as it is currently understood, does not provide an adequate explanation for the increase in allergic disease in North American inner cities.'}

The ubiquitous nature of VOCs, including formaldehyde and the resultant cocktail of chemicals, within a closed indoor microenvironment, may set off complex and subtle chemical reactions. Research from the prospective Avon Longitudinal Study of Parents and Children (ALSPAC) has shown that at numerous time points in a child's development, beginning in the prenatal period, exposure to chemicals from a range of domestic products is associated with persistent wheezing in preschool children [23]. The most recent analysis indicates that total chemical burden in the home is most likely to effect the nonatopic child [24]. This finding might be a part of a 
mechanism for the hygiene hypothesis whereby 'hygiene' may in fact be a proxy for exposure to chemicals rather than a reduced exposure to microbial or bacterial factors. This could directly link with increased use of some chemicals and subsequent bacterial resistance.

The hygiene hypothesis, as currently understood, does not provide an adequate explanation for the increase in allergic disease in North American inner cities, where asthma is increasing among children who live in very poor housing [25]. It is also known that those in the lowest social classes with the highest percentage of smokers are using domestic chemical cleaning products most frequently. The ALSPAC study also addressed the question of whether cleanliness in terms of general hygiene, such as frequency of washing, was associated with increased risk of atopic dermatitis. At 6 and 30-42 months of age, children showed a moderate increase in atopic dermatitis associated with higher levels of personal hygiene [26].

\section{Confounding behavior}

The question remains, therefore, as to whether increased hygiene as defined by apparent cleanliness traits, may be a mask for increased use of chemicals. Whether behavior can explain the hygiene hypothesis is addressed by van Schayck and Knottnerus [27].

'...behavior could be a confounder

where it is associated with both the

exposure (infection) and the

outcome (respiratory illness).'

Much of the research on the hygiene hypothesis is based on cross-sectional studies where no causal relationships can be measured with sufficient validity, while in retrospective cohort studies exposure could be influenced by behavior. For instance, behavior of the parent could confound both the sibling and daycare attendance effect. If the first two children in a family have asthma, the parents may not wish to have more children if they are concerned that these might also be asthmatic. This might suggest a positive association between smaller family size and occurrence of asthma in children. A child susceptible to respiratory illness might also be less likely to be put in daycare than a nonsusceptible child. Asthmatic parents would perhaps be concerned that their child would be exposed to infections, this behavior being fashioned by their own experiences and the effect such infections apparently had on their own health. Therefore, behavior could be a confounder where it is associated with both the exposure (infection) and the outcome (respiratory illness).

The healthy worker effect seen in occupational studies may be a confounder for the negative association between exposure to microbial products associated with farming and the occurrence of asthma. Vogelzang et al. found allergic adolescents were less likely to choose a farming profession compared to nonallergic adolescents [28]. There may be a similar mechanism acting in the family where allergic parents and parents of children with asthma might be less likely to decide to have a cat or dog in their households than other parents.

'Research might now turn
to the chemical constituents of
household products used in the
home at crucial time points in a
child's development.'

However, van Schayck and Knottnerus do not address whether behavior can explain the use of chemicals in the home [27]. Thus, a belief that asthma or respiratory ill health may be improved in a 'cleaner' environment, would favor the use of chemicals via domestic cleaning sprays and antibacterial products. If these reduce microbes or bacteria there may be an eventual resistance of organisms. Furthermore, many of the chemicals now used in the home contain fragrances that merely mask odors such as tobacco smoke. It is of interest that several studies have reported that low-to-moderate exposure to artificial fragrances can significantly worsen asthma in a large percentage of asthmatics [29-31]. Research might now turn to the chemical constituents of household products used in the home at crucial time points in a child's development.

\section{Financial \& competing interests disclosure}

The author has no affiliations or financial involvement with any organization or entity with a financial interest in or financial conflict with the subject matter or materials discussed in the manuscript. This includes employment, consultancies, honoraria, stock ownership or options, expert testimony, grants or patents received or pending, or royalties.

No writing assistance was utilized in the production of this manuscript. 


\section{Bibliography}

1. Landrigan PJ, Schechter CB, Lipton JM, Fahs MC, Schwartz J: Environmental pollutants and disease in American children: estimates of morbidity, mortality, and costs for lead poisoning, asthma, cancer, and developmental disabilities. Environ. Health Perspect. 110(7), 721-728 (2002).

2. Hofhuis W, de Jongste JC, Merkus PJ: Adverse health effects of prenatal and postnatal tobacco smoke exposure on children. Arch. Dis. Child. 88(12), 1086-1090 (2003).

3. Butland BK, Strachan DP, Anderson HR: The home environment and asthma symptoms in childhood: two population based case-control studies 13 years apart. Thorax 52(7), 618-624 (1997).

4. Frosh AC, Sandhu G, Joyce R, Strachan DP: Prevalence of rhinitis, pillow type and past and present ownership of furred pets. Clin. Exp. Allergy. 29(4), 457-460 (1999).

5. Nafstad P, Nystad W, Jaakkola JJ: The use of a feather quilt, childhood asthma and allergic rhinitis: a prospective cohort study. Clin. Exp. Allergy. 32(8), 1150-1154 (2002).

6. Bornehag CG, Sundell J, Weschler CJ et al: The association between asthma and allergic symptoms in children and phthalates in house dust: a nested case-control study. Environ. Health Perspect. 112, 1393-1397 (2004).

7. Strachan DP: Hay fever, hygiene, and household size. Br. Med. J. 299, 1259-1260 (1989).

8. von Mutius E: Asthma and allergies in rural areas of Europe. Proc. Am. Thorac. Soc. 4, 212-216 (2007).

9. Seiskari T, Kondrashova A, Viskari $\mathrm{H}$ et al.: Allergic sensitization and microbial load a comparison between Finland and Russian Karelia. Clin. Exp. Immunol. 148, 47-52 (2007).

10. Benn CS, Melbye M, Wohlfahrt J, Bjorksten B, Aaby P: Cohort study of sibling effect, infectious diseases, and risk of atopic dermatitis during first 18 months of life. Br. Med. J. 328, 1223 (2004).
11. Flohr C, Pascoe D, Williams HC: Atopic dermatitis and the 'hygiene hypothesis': too clean to be true? Brit. J. Dermatol. 152(2), 202-216 (2005).

12. Bremner SA, Carey IM, DeWilde S et al: Infections presenting for clinical care in early life and later risk of hay fever in two UK birth cohorts. Allergy 63, 274-283 (2008).

13. Kemp A, Bjorksten B: Immune deviation and the hygiene hypothesis: a review of the epidemiological evidence. Pediatr. Allergy Immunol. 14(2), 74-80 (2003).

14. Peden DP, Bush RK: Advances in environmental and occupational disorders. Advances in asthma, allergy, and immunology series. J. Allergy Clin. Immunol.119, 1127-1132 (2007).

15. Pinkerton KE, Joad JP: Mammalian respiratory system and critical windows of exposure for children's health. Environ. Health Perspect. 108, 457-462 (2000).

16. Zock JP, Kogevinas M, Sunyer J, Jarvis D, Torén K, Antó JM: European Community Respiratory Health Survey: asthma characteristics in cleaning workers, workers in other risk jobs and office workers. Eur. Respir. J. 20(3), 679-685 (2002).

17. Farrow A, Taylor H, Northstone K, Golding J: The ALSPAC Study Team: Symptoms of mothers and infants related to total volatile organic compounds in household products. Arch. Environ. Health. 58(10), 633-641 (2003).

18. Rumchev K, Spickett J, Bulsara M, Phillips M, Stick S: Association of domestic exposure to volatile organic compounds with asthma in young children. Thorax 59(9), 746-751 (2004).

19. US EPA: Environmental Threats to Children's Health. Environmental Protection Agency, Washington, DC, USA (1996).

20. National Academy of Sciences: Toxicity Testing: Needs and Priorities. National Academy Press, Washington, DC, USA (1984).
21. Goldman LR, Koduru SH: Chemicals in the environment and developmental toxicity to children: a public health and policy perspective. Environ. Health Perspect. 108(Suppl. 3), 443-448 (2000).

22. Kjaergaard SJ, Molhave L, Pedersen OF: Human reactions to a mixture of indoor air volatile organic compounds. Atmos. Environ. 25a(8), 1417-1426 (1991).

23. Sherriff A, Farrow A, Golding J; the ALSPAC Study Team: Frequent use of chemical household products is associated with persistent wheezing in pre-school age children. Thorax 60(1), 45-49 (2005).

24. Henderson J, Sherriff A, Farrow A, Ayres J: Household chemicals, persistent wheezing and lung function: effect modification by atopy? Eur. Respir. J. 3, 547-554 (2008).

25. Platts-Mills TAE, Erwin E, Heymann P, Woodfolk J: Is the hygiene hypothesis still a viable explanation for the increased prevalence of asthma? Allergy 60(S79), 25-31 (2005).

26. Sherriff A, Golding J; the ALSPAC Study Team: Hygiene levels in a contemporary population cohort are associated with wheezing and atopic eczema in preschool infants. Arch. Dis. Child. 87, 26-29 (2002).

27. van Schayck CP, Knottnerus JA: Can the 'hygiene hypothesis' be explained by confounding by behavior? J. Clin. Epidemiol. 57(5), 435-437 (2004).

28. Vogelzang PFJ, van der Gulden JWJ, Tielen MJM, Folgering HTM, van Schayck CP: Health-based selection for asthma, but not for chronic bronchitis in pig farmers: an evidence-based hypothesis. Eur. Respir J. 13(1), 187-189 (1999).

29. Kumar P, Caradonna-Graham VM, Gupta $S$, Cai X, Rao PN, Thompson J: Inhalation challenge effects of perfume scent strips in patients with asthma. Ann. Allergy. 75(5), 429-33 (1995).

30. Millqvist E, Lowhagen O: Placebo controlled challenges with perfume in patients with asthma-like symptoms. Allergy 51(6), 434-439 (1996).

31. Shim C, Williams MH: Effect of odors in asthma. Am. J. Med. 80(1), 18-22 (1986). 